\title{
Distinct Characteristics of COVID-19 Infection in Children
}

\author{
Xuejiao Han ${ }^{1+}$, Xuemei $\mathrm{Li}^{2 \dagger}$, Yinan Xiao ${ }^{3}$, Ruoning Yang ${ }^{3}$, Yang Wang ${ }^{1}$ and Xiawei Wei ${ }^{1 *}$ \\ ${ }^{1}$ Laboratory of Aging Research and Cancer Drug Target, State Key Laboratory of Biotherapy and Cancer Center, National \\ Clinical Research Center for Geriatrics, West China Hospital, Sichuan University, Chengdu, China, ${ }^{2}$ Quality Management \\ Department, Southwestern Hospital, Army Medical University, Chongqing, China, ${ }^{3}$ West China School of Medicine, West \\ China Hospital, Sichuan University, Chengdu, China
}

SARS-CoV-2, a member of the family coronaviridae, has triggered a lethal pandemic termed coronavirus disease 2019 (COVID-19). Pediatric patients, mainly from families with a cluster of infection or a history of exposure to epidemic areas, get infected via direct contacts or air-borne droplets. Children (aged below 18 years) are susceptible to COVID-19, with an average incubation period of about 6.5 days. Most cases present asymptomatic or common cold symptoms such as fever, cough, and myalgia or fatigue, which is milder than adult patients. Besides, most abnormal laboratory and radiologic findings in children with COVID-19 are non-specific. Since no specific chemotherapeutic agents have been approved for children, timely preventive methods could effectively forestall the transmission of SARS-CoV-2. To date, mostly studied cases have been adults with COVID-19, whereas data on pediatrics patients remain poorly defined. We herein conducted a literature review for papers published in PubMed and medRxiv (preprints) between December 2019 and December 2020 that reported on pediatrics patients (aged below 18 years) with a confirmed COVID-19 diagnosis. In this review, we summarized and discussed the pathogenesis, epidemiology, and clinical management of COVID-19 in pediatrics patients to improve our understanding of this new disease in children.

Keywords: pediatrics, COVID-19, SARS-COV-2, infection, characteristics, children

\section{INTRODUCTION}

In December 2019, a new type of pneumonia of unknown etiology quickly spread. An unknown beta-CoVs was detected by unbiased sequencing in the samples from patients with new pneumonia (1), which was later termed SARS-CoV-2 by the International Committee on Taxonomy of Viruses (ICTV) based on its close relationship with SARS-CoV. Both SARS-CoV and MERS-CoV belong to beta-CoVs and share 79.6 and 50\% identity with SARS-CoV-2 $(2,3)$. Currently, COVID-19 has spread widely around the world, affecting more than 200 countries and territories. The population of all ages is susceptible to COVID-19 via respiratory tract infection or direct contact due to the absence of specific immunity (4).

Even though the overall mortality for children is about $1 \%$ and severe complications are less likely to occur, the possibility of children being infected is the same as that of adults (5). The difference in disease development between children and adults may lead to distinct clinical management. Therefore, we conducted a literature review for papers published in PubMed and medRxiv (preprints) between December 2019 and December 2020 that reported on pediatrics 
patients (aged below 18 years) with a confirmed COVID19 diagnosis. In this review, we focus on the pathogenesis, epidemiologic features, clinical symptoms, diagnostic criteria, and prevention methods of children with COVID-19, and expect to provide systematic understanding and new insight into the diagnosis as well as management of children infected with COVID-19.

\section{PATHOGENESIS}

SARS-CoV-2 enters cells by binding to the receptor, angiotensinconverting enzyme 2 (ACE2) through $\mathrm{S}$ protein (6). ACE2 is highly expressed in alveolar epithelium, heart, renal tubules and intestinal epithelial cells (7-9). Severe complications of COVID19 , such as multiple organ dysfunction syndromes (MODS) and acute respiratory distress syndrome (ARDS), might be caused by dysregulated immune response and cytokine storms (10-12). Recently, many severe cases presenting persistent fever and the involvement of two or more organ systems in children with COVID-19 have been reported, which is termed as multisystem inflammatory syndrome (MIS-C). The symptoms of MIS-C are similar to Kawasaki Disease (KD) and toxic shock-like syndrome (13). MIS-C was firstly reported in Europe $(13,14)$. Pediatrics patients diagnosed with MIS-C are less common in Asia countries than in Europe, with only one case in Korea now (15). Some studies hypothesized that the pathogenesis of MIS-C might be attributable to genomic variation of virus and post-infectious immune dysregulation (16). Recently, immunophenotype studies have demonstrated that some MIC-S patients have a peculiar B cell response with an increase of plasmablast $(\mathrm{PB})$ proportion $(17,18)$. However, the specific pathological process is still unclear, and further studies evaluating the etiopathogenesis of MIS-C are essential for developing the treatment strategies.

\section{EPIDEMIOLOGIC FEATURES}

Children of all ages are susceptible to COVID-19 (19). Despite the higher incidence of COVID-19 in older children, infants ( $<1$ year) seem to be the most vulnerable due to a high hospitalization rate (20). The average incubation period for COVID-19 in children is about 6.5 days, which is longer than the 5.4 days reported in adults (21). There is no significant gender difference in pediatric patients (19). Of the 2,135 pediatric patients, $94.1 \%$ of cases were either asymptomatic or diagnosed with a mild to moderate symptom, only $5.8 \%$ had developed severe complications compared with $18.5 \%$ in adult patients (19). Several factors could account for severe outcomes among children with COVID-19 infection, such as immunocompromised condition, pulmonary pathology, the age of infants ( $<3$ months) and patients' underlying diseases, including asthma and obesity (22).

Even though the symptoms of pediatric patients are mild, children are as susceptible as adults. Recent virologic data indicated that viral load in the asymptomatic patient was not significantly different from that in the symptomatic patients, which suggested asymptomatic patients could be the potential source of COVID-19 infection $(23,24)$. In addition, nasopharyngeal SARS-CoV-2 viral loads in infected children were similar to those in other age groups, indicating that children were at a similar risk of infection to adults (25). However, all data suggest that SARS-CoV-2 transmission from children to adults or other children is infrequent (26). The incidence rate of COVID-19, though low in pediatric patients, varies from study to study in different countries (Table 1). The variation of incidence rate is probably due to the testing policy and testing availability. According to the report from the Centers for Disease Control and Prevention (CDC) in the United States, SARS-CoV-2 pediatrics patients ( $<18$ years) have accounted for $10.2 \%$ of all reported cases by December 14, 2020 (39). However, mortality in infected children is $<1 \%$ (39).

Different from the various transmission routes of adults, pediatric patients get infected mainly from families with a cluster of infection or a history of exposure to epidemic areas (40). On January 11, 2020, in Shenzhen, Guangdong, China, one asymptomatic child (aged 10 years) was confirmed, whose parents and grandparents suffered COVID-19 earlier (4). Although schools and universities have been fully reopened, few infected cases were identified, suggesting that children play a potentially minor role in SARS-CoV-2 transmission within schools and beyond (41). On the other hand, Kang Zhang et al. reported that real-time polymerase chain reaction (RTPCR) results in rectal swabs were persistently positive even after nasopharyngeal swabs turned negative (42). Therefore, they hypothesized the fecal-oral transmission and doubted whether children could facilitate it if they were not toilet trained. ACE2 is highly expressed in stratified epithelial cells of upper esophageal and intestinal epithelial cells in the ileum and colon (9). And the fecal-oral transmission does exist with other respiratory viruses (43). Although fecal-oral transmission has not been confirmed, it cannot be ruled out.

The reason for the lower infection rate among children might be the closure of schools and kindergartens reduces the exposure of children to the virus, and children are not tested for SARS$\mathrm{CoV}-2$ as frequently as adults due to mild or absent symptoms. For example, in a study of children (aged below 22 years) tested for SARS-CoV-2 at a community, the result showed that $28.2 \%$ had a positive PCR test, much higher than the reported incidence of COVID-19 in pediatric patients (44).

\section{CLINICAL PRESENTATION}

The clinical manifestations of pediatric patients are mostly mild and non-specific. Common symptoms among these early confirmed patients included fever, cough, and myalgia or fatigue (45-47). The median duration of fever in children lasts 3 days compared to 10 days in adults (48). A few children have upper respiratory symptoms, such as nasal congestion, sore throat and runny nose $(4,46)$. Specifically, gastrointestinal symptoms could be initial symptoms in some cases, including nausea, vomiting, diarrhea and abdominal pain, and these pediatric patients are more likely to develop the more severe clinical condition $(49,50)$. And gastrointestinal symptoms are twice as common in children 
TABLE 1 | Clinical characteristics among COVID-19 pediatrics patients in different countries (27-38).

\begin{tabular}{|c|c|c|c|c|c|c|}
\hline \multicolumn{7}{|l|}{ Characteristics } \\
\hline Number of patients & 2,572 & 171 & 100 & 58 & 30 & 51 \\
\hline Median age (range), yr & $11(0-17)$ & 6.7 (1 day $-15 \mathrm{yr})$ & $3.3(0-17.5)$ & $\begin{array}{l}2.9 \text { (3.3 months }-12.2 \\
y r)\end{array}$ & 5.5 ( 1 day -15 yr) & 10 \\
\hline 1 to $<6 \mathrm{yr}$ & NA & $40(23.4)$ & $15(15.0)$ & NA & $11(36.7)$ & $8(15.7)$ \\
\hline $6-10 \mathrm{yr}$ & NA & $58(33.9)$ & $21(21.0)$ & NA & NA & NA \\
\hline$>10 \mathrm{yr}$ & NA & $42(24.6)$ & $24(24.0)$ & NA & NA & NA \\
\hline Male-No./total No. (\%) & $1,408 / 2,490(56.5)$ & 104/171 (60.8) & $57 / 100(57.0)$ & 37/58 (63.8) & $14 / 30(46.7)$ & $26 / 51(51.0)$ \\
\hline Coexisting conditions-No./total No. (\%) & 80/345 (23.2) & NA & 27/100 (27.0) & 23/58 (39.7) & 7/30 (23.3) & 8/51 (15.7) \\
\hline Survived-No./total No. (\%) & 2,569/2,572 (99.9) & 170/171 (99.4) & $100 / 100(100.0)$ & 57/58 (98.3) & $30 / 30(100.0)$ & $48 / 51(94.1)$ \\
\hline \multicolumn{7}{|l|}{ Symptoms-No./total No. (\%) } \\
\hline Fever & $163 / 291$ (56.0) & $71 / 171(41.5)$ & $54 / 100(54.0)$ & $41 / 58(70.7)$ & 23/30 (76.7) & $40 / 51(78.4)$ \\
\hline \multicolumn{7}{|l|}{ Temperature } \\
\hline$\leq 37.5^{\circ} \mathrm{C}$ & 128/291 (44.0) & 100/171 (58.5) & 46/100 (46.0) & NA & NA & NA \\
\hline $37.6-38.0^{\circ} \mathrm{C}$ & NA & $16 / 171(9.4)$ & 15/100 (15.0) & NA & NA & NA \\
\hline $38.1-39.0^{\circ} \mathrm{C}$ & NA & $39 / 171(22.8)$ & 28/100 (28.0) & NA & NA & NA \\
\hline$>39.0^{\circ} \mathrm{C}$ & NA & $16 / 171(9.4)$ & $11 / 100(11.0)$ & NA & NA & NA \\
\hline Cough & 158/291 (54.3) & $83 / 171$ (48.5) & $44 / 100$ (44.0) & 42/58 (72.4) & 16/30 (53.3) & $34 / 51(66.7)$ \\
\hline Diarrhea & $37 / 291(12.7)$ & 15/171 (8.8) & 9/100 (9.0) & $7 / 58(12.1)$ & 3/30 (10.0) & $7 / 51(13.7)$ \\
\hline Myalgia & 66/291 (22.7) & NA & NA & 2/58 (3.4) & NA & NA \\
\hline Runny nose & $21 / 291(7.2)$ & NA & NA & NA & 0 & NA \\
\hline Region & Argentina & Brazil & Ethiopia & Perú & UK & Korea \\
\hline Incidence (\%) & NA & 19.1 & NA & 19.9 & 0.8 & NA \\
\hline Number of patients & 578 & 66 & 90 & 91 & 451 & 91 \\
\hline Median age (range), yr & $4.2(0.7-11.2)$ & 7.0 (24 day-18 yr) & $\begin{array}{l}15 \text { (6 } \\
\text { months-18 yr) }\end{array}$ & $6(3-10)$ & $3.9(0.3-12.9)$ & $11(0.07-18)$ \\
\hline \multicolumn{7}{|l|}{ Age distribution, No. (\%) } \\
\hline$<1 \mathrm{yr}$ & NA & $13(19.7)$ & NA & NA & $162(35.9)$ & $6(6.6)$ \\
\hline 1 to $<6 \mathrm{yr}$ & NA & NA & NA & NA & NA & $13(14.3)$ \\
\hline $6-10 \mathrm{yr}$ & NA & NA & $16(17.8)$ & NA & NA & $23(25.3)$ \\
\hline$>10 \mathrm{yr}$ & NA & NA & $64(71.1)$ & NA & $150(33.2)$ & 49 (53.8) \\
\hline \multirow[t]{2}{*}{ Male-No./total No. (\%) } & $315 / 578(54.5)$ & $44 / 66(66.7)$ & $33 / 90(36.7)$ & $58 / 91(63.7)$ & $256 / 450(56.9)$ & $53 / 91(58.2)$ \\
\hline & & & & 49/91 (53.8) & & \\
\hline Coexisting conditions-No./total No. (\%) & 204/578 (35.3) & $50 / 66(75.8)$ & 3/90 (3.3) & & 195/451 (43.2) & 6/91 (6.6) \\
\hline \multicolumn{7}{|c|}{ Exposure to SARS-COV-2-No./total No. (\%) } \\
\hline Family cluster & NA & NA & NA & 24/91 (26.4) & NA & $57 / 91(62.6)$ \\
\hline
\end{tabular}


TABLE 1 | Continued

\begin{tabular}{|c|c|c|c|c|c|c|}
\hline \multicolumn{7}{|l|}{ Characteristics } \\
\hline Region & Argentina & Brazil & Ethiopia & Perú & UK & Korea \\
\hline Other exposure & NA & NA & NA & $4 / 91(4.4)$ & NA & 30/91 (33.0) \\
\hline Unknown exposure & $156 / 578(27.0)$ & 39/66 (59.0) & 49/90 (54.4) & $63 / 91(69.2)$ & NA & 4/91 (4.4) \\
\hline Survived-No./total No. (\%) & $577 / 578(99.8)$ & 65/66 (98.5) & 90/90 (100.0) & $82 / 91(90.1)$ & 448/451 (99.3) & $91 / 91(100.0)$ \\
\hline \multicolumn{7}{|c|}{ Symptoms-No./total No. (\%) } \\
\hline Fever & $207 / 400(51.7)$ & $37 / 66(56.1)$ & $5 / 90(5.6)$ & 36/91 (39.6) & $306 / 418$ (73.2) & 62/91 (68.1) \\
\hline $\begin{array}{l}\text { Temperature } \\
\leq 37.5^{\circ} \mathrm{C}\end{array}$ & NA & NA & NA & NA & NA & NA \\
\hline $37.6-38.0^{\circ} \mathrm{C}$ & NA & NA & NA & NA & NA & 35/91 (38.5) \\
\hline $38.1-39.0^{\circ} \mathrm{C}$ & NA & NA & NA & NA & NA & NA \\
\hline$>39.0^{\circ} \mathrm{C}$ & NA & NA & NA & NA & NA & NA \\
\hline Cough & $40 / 400(10.0)$ & 23/66 (34.8) & 20/90 (22.2) & 18/91 (19.8) & $175 / 431(40.6)$ & $37 / 90(41.1)$ \\
\hline Diarrhea & NA & NA & NA & NA & $58 / 431(13.4)$ & $11 / 90(12.2)$ \\
\hline Rhinorrhea & $39 / 400(9.7)$ & NA & NA & NA & NA & 24/90 (26.7) \\
\hline Fatigue & NA & NA & $5 / 90(5.6)$ & NA & 103/431 (23.9) & 5/89 (5.6) \\
\hline Shortness of breath & NA & 10/66 (15.2) & NA & 12/91 (13.2) & 124/389 (31.9) & $1 / 77(1.3)$ \\
\hline Sore throat & $49 / 400(12.2)$ & NA & 9/90 (10.0) & NA & 40/431 (9.3) & 22/77 (28.6) \\
\hline NauseaNomiting & NA & NA & $4 / 90(4.4)$ & $11 / 91(12.1)$ & 120/380 (31.6) & 6/90 (6.7) \\
\hline Abdominal pain & 15/400 (3.7) & NA & NA & NA & 66/431 (15.3) & 6/77 (7.8) \\
\hline Headache & $37 / 400(9.2)$ & NA & 9/90 (10.0) & NA & 43/431 (10.0) & 12/77 (15.6) \\
\hline Myalgia & NA & NA & NA & NA & $28 / 431(6.5)$ & $7 / 77(9.1)$ \\
\hline Runny nose & NA & NA & $5 / 90(5.6)$ & NA & $61 / 431(14.1)$ & NA \\
\hline
\end{tabular}

as in adults $(51,52)$. Some infected newborns may present only low spirits, loss of appetite, and shortness of breath $(22,53)$. Severe pediatric cases show dyspnea and cyanosis and may advance to ARDS, septic shock, refractory metabolic acidosis, MODS, and coagulation dysfunction $(21,50)$. According to one analysis from China, younger children, especially infants and pre-school children are more susceptible to severe symptoms $(10.6 \%<1$-year-old vs. $3 \% \geq 16$ years old) $(19)$. The potential explanation is the immaturity of the immune system in infants and pre-school children. Recently, Kawasaki-like disease was reported among children with COVID-19 (13). This disease is also named pediatric inflammatory multisystem syndrome (PIMS) or MIS-C due to its clinical manifestation associated with multisystem inflammation such as conjunctivitis, myocarditis, meningitis and coronary vessel inflammation $(13,54)$. Feldstein et al. reported that $33 \%$ of the diagnosed infected children had Kawasaki-like clinical symptoms (55). Intriguingly, a 14-yearold boy diagnosed and treated for orchiepididymitis, however, confirmed COVID-19 infection without respiratory symptoms, suggesting the possibility of testicular involvement in COVID19 (56). Different clinical features of pediatrics patients among countries are summarized in Table 1.

The reason why children have milder symptoms than adults remains unclear. According to recent research, several factors are worth considering (Figure 1). The first reason is the higher expression level of ACE2 in children. According to the analysis from China, older adults ( $>50$ years) who were more likely to develop into serious pneumonia, presented decreased expression of ACE2 when compared to children. This may impact disease severity and recovery from pneumonia caused by SARS-CoV2 infection in older patients (57). The second possibility is trained immunity, which means training innate immunity to generate immune memory for non-specific immune protection (58). Thirdly, the difference in innate and adaptive immunity between adults and children should also be taken into account. And the antibodies following other coronavirus infections may play a protective role in SARS-CoV-2 infection (59). Finally, compared with the elderly, children had no underlying diseases but a healthy respiratory tract without exposure to cigarettes and polluted air.

\section{LABORATORY AND RADIOLOGIC EXAMINATIONS}

Most abnormal laboratory findings in children with COVID-19 are non-specific. The white blood cell count is typically normal or reduced with decreased lymphocyte and/or neutrophil counts $(27,60)$. The levels of C-reactive protein and procalcitonin (PCT) can be normal or elevated. However, children have a much lower prevalence of increased C-reactive protein than adults, suggesting a much milder immunological response and less immune damage (61). The best markers for diagnosing the severity of the disease in children are the levels of bilirubin and hepatic enzymes $(62,63)$. During April 2020, a surge of PIMS cases presenting a hyper-inflammatory state including elevated 


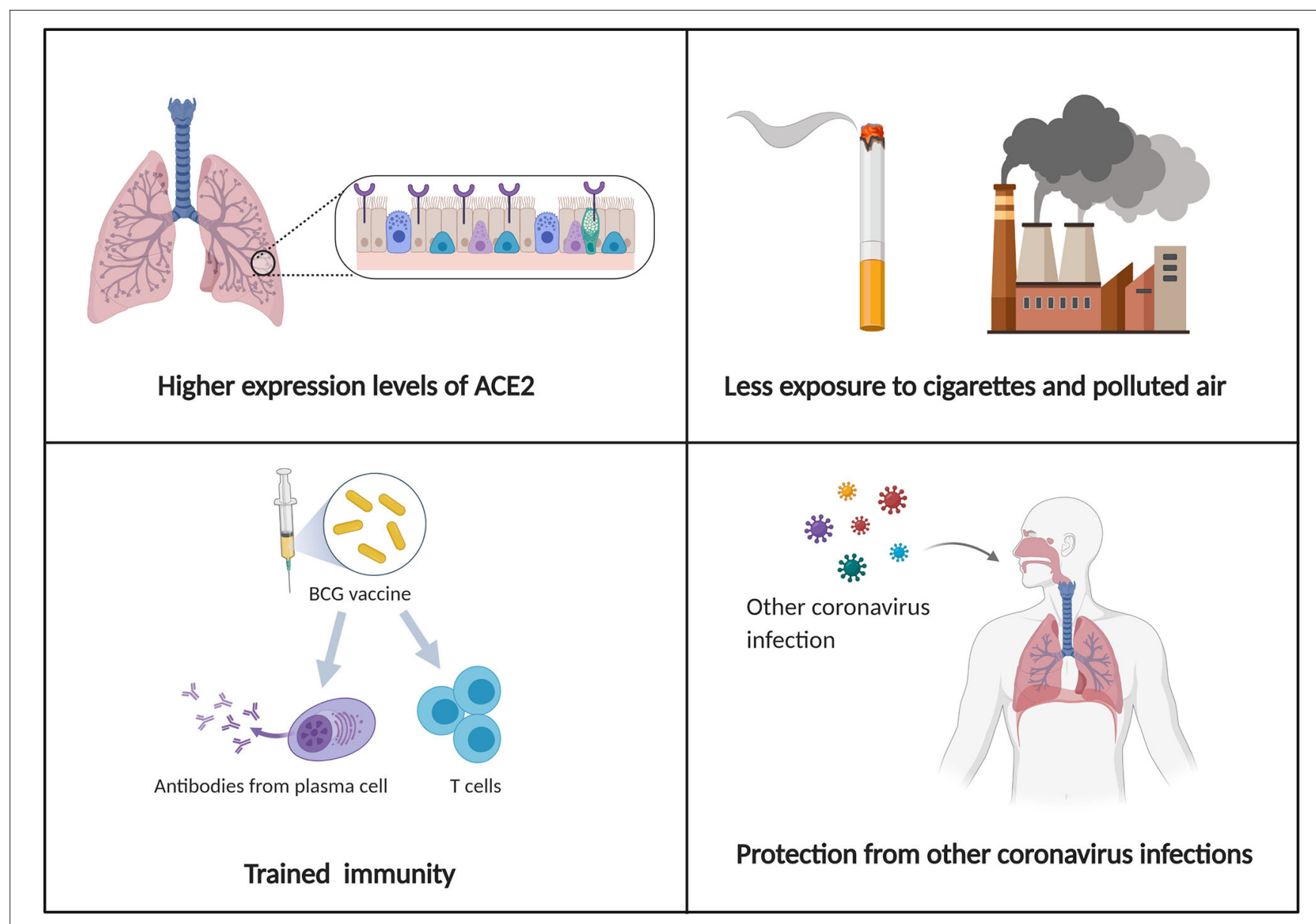

FIGURE 1 | Schematic illustration of possible mechanisms for explaining why children have milder symptoms and a better prognosis than adults.

levels of C-reactive protein, PCT, ferritin, and D-dimers, as well as markers of myocarditis (13).

RT-PCR is the most common to detect SARS-CoV-2 nucleic acid. Since the virus exists in serum, urine, stool, upper, and lower respiratory tract specimens, nasopharyngeal and oropharyngeal swabs, bronchoalveolar lavage, or tracheal aspirates might be helpful $(4,64)$. The result from Liu et al. showed that the median viral shedding duration detected in nasopharyngeal swabs, oropharyngeal swabs, and stools were 13, 4, and 43 days, respectively, suggesting the possibility of fecal-oral transmission (65). Neutralizing antibody (NAb) response is also helpful for the diagnosis. However, negative antibody tests cannot exclude COVID-19 as it needs a certain time period for the body to produce serum-specific antibodies after infection (65).

The sensitivity of chest X-ray might be lower than that of computed tomography (CT) scan. Infected pediatric patients do not commonly present abnormalities in chest X-ray at the early stage, with occasional interstitial changes (66). Chest CT abnormalities observed in pediatric patients include unilateral or bilateral multiple patchy shadows, nodular ground-glass opacities (GGO) or consolidations with a surrounding halo sign (67). The sensitivity of chest CT in diagnosing COVID-19 is greater than that of RT-PCR (98 vs. 71\%) (68). In addition, lung ultrasound (LUS) is also used as a diagnostic tool. Recent research from Italy indicated LUS abnormalities including subpleural consolidations and confluent B-lines in eight children with COVID-19 infection (69).

\section{DIAGNOSIS}

The criteria for COVID-19 diagnosis in children are based on epidemiology, clinical manifestations, and laboratory testing to confirm SARS-CoV-2 infection. The case definition and clinical classification of children are summarized in Table 2. Also, co-infections such as mycoplasma, influenza A and B, respiratory syncytial virus, Epstein-Barr virus, cytomegalovirus, parainfluenza, and adenovirus should take into consideration in diagnosis since co-infections rate are up to $79 \%$ in children (67).

\section{THERAPY AND PREVENTION}

Until now, no concrete evidence has demonstrated the effectiveness and safety of specific drugs against COVID-19. 
TABLE 2 | Case definition and clinical classification of children from the Chinese updated consensus statement (March 24, 2020) (22).

\section{CASE DEFINITION}

A suspected case is defined as a case that meets: one epidemiologic criterion and two clinical criteria

Epidemiologic criteria:

1. Children with a travel or residence history in a community with infected cases reported in China or a country or region with a serious epidemic within 14 days prior to disease onset (with the global pandemic of COVID-19, imported cases deserve attention)

2. Children with a history of contacting patients infected with SARS-CoV-2 within 14 days prior to disease onset

3. Children with a history of contacting patients with fever or respiratory symptoms from communities with reported cases in China or countries or regions with serious epidemic within 14 days prior to disease onset

4. Clustered cases: two or more cases with fever and/or respiratory symptoms within 14 days in small groups (such as family members, school classmates, etc.)

5. Newborns delivered by mothers with confirmed infection.

\section{Clinical criteria:}

1. Fever, fatigue, dry cough, and/or other respiratory symptoms; some pediatric patients may have low-grade fever or no fever

2. Patients with the following chest imaging findings: single or multiple localized ground-glass opacities in the form of light cloud or fine mesh, with thickened blood vessels shadows inside the lesions; localized consolidation, located under the pleura or near the bronchial blood vessel bundles, most in the bilateral lower lobes of the periphery of the subpleural lung; increased ground-glass shadows; large-scale consolidation; diffused consolidation of unilateral or bilateral lungs, with ground-glass opacities, bronchial inflation signs

3. In the early phase of the disease, white blood cell count is normal or decreased, or with decreased lymphocytes count

4. No other pathogens are detected which can fully explain the clinical manifestations.

A confirmed case is defined as a case that meets any of the following criteria:

1. Testing positive for SARS-CoV-2 by real-time PCR

2. Genetic sequencing of respiratory tract or blood samples is highly homologous with the known SARS-CoV-2

3. Both serum-specific antibodies $\lg M$ and $\lg G$ are positive

4. Serum-specific antibody lgG changed from negative to positive or increased 4 -folds or higher than that in the acute phase during the recovery period.

\section{CLINICAL CLASSIFICATION}

1. Asymptomatic infection (silent infection)

Testing positive for SARS-CoV-2, but without clinical symptoms or abnormal chest imaging findings

2. Acute upper respiratory tract infection

With only fever, cough, pharyngeal pain, nasal congestion, fatigue, headache, myalgia or discomfort, etc., and without signs of pneumonia by chest imaging or sepsis

3. Mild pneumonia

With or without fever, with respiratory symptoms such as cough; and chest imaging indicating changes of viral pneumonia, but not reaching the criteria of severe pneumonia

4. Severe pneumonia

a. Polypnea: $\geq 60$ times/min ( $<2$ months), $\geq 50$ times/ $\min (2-12$ months), $\geq 40$ times/min (1-5 years), $\geq 30$ times/min (>5 years) (after ruling out the effects of fever and crying)

b. Oxygen saturation $<92 \%$ under a resting state

c. Dyspnea: assisted breathing (moans, nasal flaring, and three concave sign), cyanosis, intermittent apnea

d. Disturbance of consciousness: somnolence, coma, or convulsion

e. Food refusal or feeding difficulty, with signs of dehydration

f. Pulmonary high-resolution CT (HRCT) examination showing bilateral or multi-lobe infiltrates, rapid progression of disease in a short period or with pleural effusion.

5. Critical cases (require ICU care)

a. Respiratory failure requiring mechanical ventilation

b. Shock

c. Combined with other organs failure.

Children with mild or absent symptoms should be isolated at home for 2 weeks. Severe cases should be admitted to the pediatric intensive care unit (PICU) as soon as possible. Antiviral drugs targeting specific sites on different stages could effectively inhibit the virus replication in the host cells. However, their efficacy and safety remain to be determined. Antibiotics and antifungal drugs can be used only in patients with secondary bacterial infections based on the culture and antibiogram results. Given the immunomodulatory effect, corticosteroids are critical for the treatment of inflammatory and immune diseases. However, the modulatory property sometimes might lead to immune suppression that hinders the virus clearance in the host. Therefore, corticosteroids should be avoided, except when required for other indications such as MIS-C, refractory shock, or asthma exacerbation. Evidence showed that the adjunctive steroid treatment was effective and safe in pediatric patients with Kawasaki-like presentations. However, they showed resistance to intravenous immunoglobulin (IVIG) (13). In November 2020, the US Food and Drug Administration (FDA) provided Emergency Use Authorizations (EUA) for two novel virus-neutralizing monoclonal antibodies (mAbs) for the treatment of mild to moderate COVID-19 in adolescents and adults in specified high-risk groups. However, the safety and efficacy of mAbs for the COVID-19 treatment among children or adolescents remains unclear (70). Most pediatric patients with COVID19 present a good prognosis and usually recover within 12 weeks. Despite a higher hospitalization rate of infants, children are rarely admitted to intensive care units (ICU) in general (71).

Emergent health conditions all over the world accelerate vaccine development, clinical testing, and usage. The vaccine currently available mainly falls into six categories: inactivated virus, live attenuated virus, nucleic acid-based vaccines, 
protein subunit vaccines, virus-like particles (VLPs), and recombinant viral vectors (72). Until January 21, 2021, 64 vaccine candidates have been under clinical development while 10 vaccines (inactivated vaccines, RNA-based vaccines, and non-replicating viral vectors) have been adopted for "emergent use" in America, Canada, China, Russia, Brazil, etc. $(73,74)$.

Variability of host immune responses among populations, production of secreted IgA antibodies on the mucosal surface in the upper respiratory tract, and T-cell involvement in the immune response all play roles in eliciting successful protection against SARS-CoV-2 (75). An increasing number of clinical trials have demonstrated the safety and immunogenicity of SARSCoV-2 vaccines among people ranging from 18 to 55 years old, with a low incidence of side effects such as fatigue and headache (76-78). However, lacking data concerning the safety and response rate in licensed clinical trials, vaccine efficacy in children remains unclear. It is noteworthy that Pfizer recently has included children aged from 12 to 17 into clinical trials of mRNA vaccine, which might feedback the assessment of its effectiveness shortly (79). Additionally, the occurrence of rare severe side effects such as vaccine-associated enhanced disease and Pediatric Inflammatory Multisystem Syndrome Temporally associated with SARS-CoV-2 (PIMS-TS) suggests that researchers should further explore the different immunopathogenesis of COVID19 between children and adults $(80,81)$. Vaccine-associated enhanced disease refers to severe side effects related to worse clinical outcomes after vaccination vs. without vaccination (80). In the 1960s, due to atypical measles such as fever and pneumonia observed in children after formalin-inactivated measles virus vaccination, the vaccine was prohibited (82). Despite the absence of compelling evidence regarding VAED in both animal models and human beings (80), additional attention to such rare adverse immune responses could guarantee the overall safety of populations administrated vaccines. Finally, reinfection interval or the longest possible immunity is also worth noticing since it helps indicate the optimal age for vaccination, thus providing better protective strategies for children against COVID-19 (83).

\section{REFERENCES}

1. Zhu N, Zhang D, Wang W, Li X, Yang B, Song J, et al. A novel coronavirus from patients with pneumonia in China, 2019. N Engl J Med. (2020) 382:72733. doi: 10.1056/NEJMoa2001017

2. Zhou P, Yang XL, Wang XG, Hu B, Zhang L, Zhang W, et al. A pneumonia outbreak associated with a new coronavirus of probable bat origin. Nature. (2020) 579:270-3. doi: 10.1038/s41586-020-2 012-7

3. Lu R, Zhao X, Li J, Niu P, Yang B, Wu H, et al. Genomic characterisation and epidemiology of 2019 novel coronavirus: implications for virus origins and receptor binding. Lancet. (2020) 395:565-74. doi: 10.1016/S0140-6736(20)30251-8

4. Chan JF, Yuan S, Kok KH, To KK, Chu H, Yang J, et al. A familial cluster of pneumonia associated with the 2019 novel coronavirus indicating person-toperson transmission: a study of a family cluster. Lancet. (2020) 395:514-23. doi: 10.1016/S0140-6736(20)30154-9

5. Bi Q, Wu Y, Mei S, Ye C, Zou X, Zhang Z, et al. Epidemiology and transmission of COVID-19 in 391 cases and 1286 of their close contacts in Shenzhen,
Since no specific drugs against COVID-19, it is crucial to prevent the amplification of the outbreak. Early detection of children, a possible hidden source could effectively prevent the outbreak in kindergartens or schools, especially for children who tend to develop atypical clinical characteristics but with a high virus load. Once confirmed with COVID-19 infection, the children must be quarantined at home or in the hospital to prevent close contact and human-to-human transmission. Social distance and washing hands frequently are crucial to prevent COVID-19 spread. In addition, consistent use of the mask is necessary, except for children under age two or anyone who has trouble removing it on his own. Besides, children should maintain good moods, exercise regularly and have a balanced diet to enhance their immunity (22).

\section{CONCLUSIONS}

This review summarized the updated evidence regarding the epidemiology and clinical management of COVID-19 in children. Even though most pediatric patients with COVID19 present mild symptoms and good prognosis, children are as susceptible as adults. Besides, an increasing number of COVID-19 pediatric patients with MIS-C have been reported. Further study is of paramount importance for better prevention, diagnosis and treatment of COVID-19 in children worldwide.

\section{AUTHOR CONTRIBUTIONS}

$\mathrm{XH}$ and XL were major writers of the manuscript. YX and RY designed the tables and edited the manuscript. YW researched appropriate references and reviewed the manuscript. XW developed the structure of the article, reviewed and edited the manuscript. All authors read and approved the final manuscript.

\section{FUNDING}

This work was supported by the National Natural Science Foundation of China (Grant Number 81821002).
China: a retrospective cohort study. Lancet Infect Dis. (2020) 20:911-9. doi: 10.1016/S1473-3099(20)30287-5

6. Hoffmann M, Kleine-Weber H, Schroeder S, Krüger N, Herrler T, Erichsen $S$, et al. SARS-CoV-2 cell entry depends on ACE2 and TMPRSS2 and is blocked by a clinically proven protease inhibitor. Cell. (2020) 181:27180.e278. doi: 10.1016/j.cell.2020.02.052

7. Song R, Preston G, Yosypiv IV. Ontogeny of angiotensin-converting enzyme 2. Pediatr Res. (2012) 71:13-9. doi: 10.1038/pr.2011.7

8. Kuhn JH, Li W, Choe H, Farzan M. Angiotensin-converting enzyme 2: a functional receptor for SARS coronavirus. Cell Mol Life Sci. (2004) 61:273843. doi: $10.1007 / \mathrm{s} 00018-004-4242-5$

9. Tian Y, Rong L. Review article: gastrointestinal features in COVID-19 and the possibility of faecal transmission. Aliment Pharmacol Ther. (2020) 51:843-51. doi: 10.1111/apt.15731

10. Files JK, Boppana S, Perez MD, Sarkar S, Lowman KE, Qin K, et al. Sustained cellular immune dysregulation in individuals recovering from SARS-CoV-2 infection. J Clin Invest. (2021) 131:e140491. doi: 10.1172/JCI140491

11. Chen L, Wang G, Tan J, Cao Y, Long X, Luo H, et al. Scoring cytokine storm by the levels of MCP-3 and IL-8 accurately distinguished COVID-19 
patients with high mortality. Signal Transduct Target Ther. (2020) 5:292. doi: 10.1038/s41392-020-00433-y

12. Kim JS, Lee JY, Yang JW, Lee KH, Effenberger M, Szpirt W, et al. Immunopathogenesis and treatment of cytokine storm in COVID-19. Theranostics. (2021) 11:316-329. doi: 10.7150/thno.49713

13. Verdoni L, Mazza A, Gervasoni A, Martelli L, Ruggeri M, Ciuffreda M, et al. An outbreak of severe Kawasaki-like disease at the Italian epicentre of the SARS-CoV-2 epidemic: an observational cohort study. Lancet. (2020) 395:1771-8. doi: 10.1016/S0140-6736(20)31103-X

14. Riphagen S, Gomez X, Gonzalez-Martinez C, Wilkinson N, Theocharis P. Hyperinflammatory shock in children during COVID-19 pandemic. Lancet. (2020) 395:1607-8. doi: 10.1016/S0140-6736(20)31094-1

15. Kim H, Shim JY. Multisystem inflammatory syndrome in children related to COVID-19: the first case in Korea. J Korean Med Sci. (2020) 35:e391. doi: 10.3346/jkms.2020.35.e391

16. Nakra NA, Blumberg DA, Herrera-Guerra A, Lakshminrusimha S. MultiSystem Inflammatory Syndrome in Children (MIS-C) following SARS-CoV2 infection: review of clinical presentation, hypothetical pathogenesis, and proposed management. Children. (2020) 7:69. doi: 10.3390/children7070069

17. Mathew D, Giles JR. Deep immune profiling of COVID-19 patients reveals distinct immunotypes with therapeutic implications. Science. (2020) 369:eabc8511. doi: 10.1126/science.369.6508.1203-1

18. Carter MJ, Fish M. Peripheral immunophenotypes in children with multisystem inflammatory syndrome associated with SARS-CoV-2 infection. Nat Med. (2020) 26:1701-7. doi: 10.1038/s41591-020-1054-6

19. Dong Y, Mo X, Hu Y, Qi X, Jiang F, Jiang Z, et al. Epidemiology of COVID-19 among children in China. Pediatrics. (2020) 145:e20200702. doi: 10.1542/peds.2020-0702

20. Rankin DA, Talj R, Howard LM, Halasa NB. Epidemiologic trends and characteristics of SARS-CoV-2 infections among children in the United States. Curr Opin Pediatr. (2021) 33:114-21. doi: 10.1097/MOP.0000000000000971

21. Li Q, Guan X, Wu P, Wang X, Zhou L, Tong Y, et al. Early transmission dynamics in Wuhan, China, of novel coronavirus-infected pneumonia. N Engl J Med. (2020) 382:1199-207. doi: 10.1056/NEJMoa2001316

22. Shen KL, Yang YH, Jiang RM, Wang TY, Zhao DC, Jiang Y, et al. Updated diagnosis, treatment and prevention of COVID-19 in children: experts' consensus statement (condensed version of the second edition). World $J$ Pediatr. (2020) 16:232-9. doi: 10.1007/s12519-020-00362-4

23. Zou L, Ruan F, Huang M, Liang L, Huang H, Hong Z, et al. SARS-CoV-2 viral load in upper respiratory specimens of infected patients. N Engl J Med. (2020) 382:1177-9. doi: 10.1056/NEJMc2001737

24. Wölfel R, Corman VM, Guggemos W, Seilmaier M, Zange S, Müller MA, et al. Virological assessment of hospitalized patients with COVID-2019. Nature. (2020) 581:465-9. doi: 10.1038/s41586-020-2196-x

25. Jones TC, Mühlemann B, Veith T, Biele G, Zuchowski M, Hofmann J, et al. An analysis of SARS-CoV-2 viral load by patient age. medRxiv. (2020). doi: 10.1101/2020.06.08.20125484. [Epub ahead of print].

26. Lee B, Raszka WV, Jr. COVID-19 Transmission and children: the child is not to blame. Pediatrics. (2020). 146:e2020004879. doi: 10.1542/peds.2020-004879

27. Lu X, Zhang L, Du H, Zhang J, Li YY, Qu J, et al. SARS-CoV-2 infection in children. N Engl J Med. (2020) 382:1663-5. doi: 10.1056/NEJMc2005073

28. CDC COVID-19 Response Team. Coronavirus disease 2019 in children United States, February 12-April 2, 2020. MMWR Morb Mortal Wkly Rep. (2020) 69:422-6. doi: 10.15585/mmwr.mm6914e4

29. Parri N, Lenge M. Children with Covid-19 in pediatric emergency departments in Italy. $N$ Engl $J$ Med. (2020) 383:187-90. doi: 10.1056/NEJMc2007617

30. de Ceano-Vivas M, Martín-Espín I, Del Rosal T. SARS-CoV-2 infection in ambulatory and hospitalised Spanish children. Arch Dis Child. (2020) 105:808-9. doi: 10.1136/archdischild-2020-319366

31. Soltani J, Sedighi I, Shalchi Z, Sami G, Moradveisi B, Nahidi S. Pediatric coronavirus disease 2019. (COVID-19): an insight from west of Iran. North Clin Istanb. (2020) 7:284-91. doi: 10.14744/nci.2020.90277

32. Perez Gaxiola G, Flores Rocha R, Valadez Vidarte JC, Hernandez Alcaraz M, Herrera Mendoza G, Del Real Lugo MA. Clinical and epidemiological characteristics of children with SARS-CoV-2 infection: case series in Sinaloa. medRxiv. (2020). doi: 10.1101/2020.07.07.20146332. [Epub ahead of print].
33. Raiden S, Cairoli H, Potasnik J, Di Lalla S, Chiolo MJ, Torres F, et al. Children hospitalized for COVID-19 during the first winter of the pandemic in Buenos Aires, Argentina. medRxiv. (2020). doi: 10.1101/2020.11.05.20225300. [Epub ahead of print].

34. Vieira RSR, Aguiar ELd, Evangelista NMdA, Sarrubbo SAB, Verlangieri HAR, Otsuka M. Clinical characteristics in children and adolescents with SARSCoV-2 infection: experience in a highly complex public hospital in the city of São Paulo. medRxiv. (2020). doi: 10.1101/2020.06.22.20136994. [Epub ahead of print].

35. Leulseged TW, Hassen IS, Maru EH, Zewde WC, Chamiso NW, Edo MG, et al. COVID-19 in Hospitalized Ethiopian Children: Characteristics and Outcome Profile. medRxiv. (2020). doi: 10.1101/2020.10.30.20223115. [Epub ahead of print].

36. Chiara-Chilet C, Luna-Vilchez M, Maquera-Afaray J, Salazar-Mesones B, Portillo-Alvarez D, Priale-Miranda R, et al. Clinical-epidemiological and treatment characteristics of children with COVID-19 in a tertiary referral center in Perú. medRxiv. (2020). doi: 10.1101/2020.09.18.20186866. [Epub ahead of print].

37. Swann OV, Holden KA, Turtle L, Pollock L, Fairfield CJ, Drake $\mathrm{TM}$, et al. Clinical characteristics of children and young people hospitalised with covid-19 in the United Kingdom: prospective multicentre observational cohort study. medRxiv. (2020) 2020.2007.2014.20 153320.

38. Han MS, Choi EH, Chang SH, Jin BL, Lee EJ, Kim BN, et al. Clinical characteristics and viral RNA detection in children with coronavirus disease 2019 in the Republic of Korea. JAMA Pediatr. (2021) 175:73-80. doi: 10.1001/jamapediatrics.2020.3988

39. CDC. CDC COVID Data Tracker. (2020). Vol. (2020).

40. Qiu H, Wu J, Hong L, Luo Y, Song Q, Chen D. Clinical and epidemiological features of 36 children with coronavirus disease (2019). (COVID-19) in Zhejiang, China: an observational cohort study. Lancet Infect Dis. (2020) 20:689-96. doi: 10.1016/S1473-3099(20)30198-5

41. Ismail SA, Saliba V, Lopez Bernal J, Ramsay ME, Ladhani SN. SARS-CoV2 infection and transmission in educational settings: a prospective, crosssectional analysis of infection clusters and outbreaks in England. Lancet Infect Dis. (2020) doi: 10.1101/2020.08.21.20178574. [Epub ahead of print].

42. Xu Y, Li X, Zhu B, Liang H, Fang C, Gong Y, et al. Characteristics of pediatric SARS-CoV-2 infection and potential evidence for persistent fecal viral shedding. Nat Med. (2020) 26:502-5. doi: 10.1038/s41591-020-0817-4

43. Zhu Z, Liu Y, Xu L, Guan W, Zhang X, Qi T, et al. Extra-pulmonary viral shedding in H7N9 Avian Influenza patients. J Clin Virol. (2015) 69:30-2. doi: 10.1016/j.jcv.2015.05.013

44. Simpson JN, Goyal MK, Cohen JS, Badolato GM, McGuire M, Ralph A, et al. Results of testing children for SARS-CoV-2 through a community-based testing site. J Pediatr. (2020). doi: 10.1016/j.jpeds.2020.12.030. [Epub ahead of print].

45. Ludvigsson JF. Systematic review of COVID-19 in children shows milder cases and a better prognosis than adults. Acta Paediatr. (2020) 109:1088-95. doi: 10.1111/apa.15270

46. Cai J, Xu J, Lin D, Yang Z, Xu L, Qu Z, et al. A case series of children with 2019 novel coronavirus infection: clinical and epidemiological features. Clin Infect Dis. (2020) 71:1547-51. doi: 10.1093/cid/ciaa198

47. See KC, Liew SM, Ng DCE, Chew EL, Khoo EM, Sam CH, et al. COVID19: four paediatric cases in Malaysia. Int J Infect Dis. (2020) 94:125-7. doi: 10.1016/j.ijid.2020.03.049

48. Chen J, Qi T, Liu L, Ling Y, Qian Z, Li T, et al. Clinical progression of patients with COVID-19 in Shanghai, China. J Infect. (2020) 80:e1-6. doi: 10.1016/j.jinf.2020.03.004

49. Zeng LK, Tao XW, Yuan WH, Wang J, Liu X, Liu ZS. First case of neonate infected with novel coronavirus pneumonia in China. Zhonghua Er Ke Za Zhi. (2020) 58:E009. doi: 10.3760/cma.j.issn.0578-1310.2020.0009

50. Chen F, Liu ZS, Zhang FR, Xiong RH, Chen Y, Cheng XF, et al. First case of severe childhood novel coronavirus pneumonia in China. Zhonghua Er Ke Za Zhi. (2020) 58:179-82. doi: 10.3760/cma.j.issn.0578-1310.2020.03.003

51. Chen N, Zhou M, Dong X, Qu J, Gong F, Han Y, et al. Epidemiological and clinical characteristics of 99 cases of 2019 novel coronavirus pneumonia in Wuhan, China: a descriptive study. Lancet. (2020) 395:507-13. doi: $10.1016 /$ S0140-6736(20)30211-7 
52. Huang C, Wang Y, Li X, Ren L, Zhao J, Hu Y, et al. Clinical features of patients infected with 2019 novel coronavirus in Wuhan, China. Lancet. (2020) 395:497-506. doi: 10.1016/S0140-6736(20)30183-5

53. Hong H, Wang Y, Chung HT, Chen CJ. Clinical characteristics of novel coronavirus disease 2019. (COVID-19) in newborns, infants and children. Pediatr Neonatol. (2020) 61:131-2. doi: 10.1016/j.pedneo.2020.03.001

54. Belot A, Antona D, Renolleau S, Javouhey E, Hentgen V, Angoulvant F, et al. SARS-CoV-2-related paediatric inflammatory multisystem syndrome, an epidemiological study, France, 1 March to 17 May 2020. Euro Surveill. (2020) 25:2001010. doi: 10.2807/1560-7917.ES.2020.25.22.2001010

55. Feldstein LR, Rose EB, Horwitz SM, Collins JP, Newhams MM, Son MBF, et al. Multisystem inflammatory syndrome in U.S. Children and Adolescents. N Engl J Med. (2020) 383:334-46. doi: 10.1056/NEJMoa2021680

56. Gagliardi L, Bertacca C, Centenari C, Merusi I, Parolo E, Ragazzo V, et al. Orchiepididymitis in a boy with COVID-19. Pediatr Infect Dis J. (2020) 39:e200-e2. doi: 10.1097/INF.0000000000002769

57. Zhang Z, Guo L, Huang L, Zhang C, Luo R, Zeng L, et al. Distinct disease severity between children and older adults with COVID-19: Impacts of ACE2 expression, distribution, and lung progenitor cells. Clin Infect Dis. (2021). doi: 10.1093/cid/ciaa1911. [Epub ahead of print].

58. Netea MG, Joosten LA, Latz E, Mills KH, Natoli G, Stunnenberg HG, et al. Trained immunity: a program of innate immune memory in health and disease. Science. (2016) 352:aaf1098. doi: 10.1126/science.a af1098

59. Dhochak N, Singhal T, Kabra SK, Lodha R. Pathophysiology of COVID19: why children fare better than adults? Indian J Pediatr. (2020) 87:537-46. doi: 10.1007/s12098-020-03322-y

60. Wang XF, Yuan J, Zheng YJ, Chen J, Bao YM, Wang YR, et al. Retracted: clinical and epidemiological characteristics of 34 children with 2019 novel coronavirus infection in Shenzhen. Zhonghua Er Ke Za Zhi. (2020) 58:E008. doi: 10.3760/cma.j.issn.0578-1310.2020.0008

61. Standage SW, Wong HR. Biomarkers for pediatric sepsis and septic shock. Expert Rev Anti Infect Ther. (2011) 9:71-9. doi: 10.1586/eri.10.154

62. Henry BM, Lippi G, Plebani M. Laboratory abnormalities in children with novel coronavirus disease 2019. Clin Chem Lab Med. (2020) 58:1135-38. doi: $10.1515 / \mathrm{cclm}-2020-0272$

63. Tan YP, Tan BY, Pan J, Wu J, Zeng SZ, Wei HY. Epidemiologic and clinical characteristics of 10 children with coronavirus disease 2019 in Changsha, China. J Clin Virol. (2020) 127:104353. doi: 10.1016/j.jcv.2020.1 04353

64. Bouadma L, Lescure FX, Lucet JC, Yazdanpanah Y, Timsit JF. Severe SARS-CoV-2 infections: practical considerations and management strategy for intensivists. Intensive Care Med. (2020) 46:579-82. doi: 10.1007/s00134-020-05967-x

65. Liu P, Cai J, Jia R, Xia S, Wang X, Cao L, et al. Dynamic surveillance of SARS-CoV-2 shedding and neutralizing antibody in children with COVID19. Emerg Microbes Infect. (2020) 9:1254-8. doi: 10.1080/22221751.2020.17 72677

66. Xia W, Shao J. Clinical and CT features in pediatric patients with COVID-19 infection: different points from adults. Pediatr Pulmonol. (2020) 55:1169-74. doi: $10.1002 /$ ppul.24718

67. Zimmermann P, Curtis N. COVID-19 in children, pregnancy and neonates: a review of epidemiologic and clinical features. Pediatr Infect Dis J. (2020) 39:469-77. doi: 10.1097/INF.0000000000002700

68. Fang Y, Zhang H. Sensitivity of chest CT for COVID-19: comparison to RT-PCR. Radiology. (2020) 296:E115-e7. doi: 10.1148/radiol.2020200432
69. Denina M, Scolfaro C, Silvestro E, Pruccoli G, Mignone F, Zoppo M, et al. Lung ultrasound in children with COVID-19. Pediatrics. (2020) 146:e20201157. doi: 10.1542/peds.2020-1157

70. Wolf J, Abzug MJ, Wattier RL, Sue PK, Vora SB, Zachariah P, et al. Initial guidance on use of monoclonal antibody therapy for treatment of COVID-19 in children and adolescents. J Pediatric Infect Dis Soc. (2021). doi: 10.1093/jpids/piaa175. [Epub ahead of print].

71. Wei M, Yuan J, Liu Y, Fu T, Yu X, Zhang ZJ. Novel coronavirus infection in hospitalized infants under 1 year of age in China. Jama. (2020) 323:1313-4. doi: 10.1001/jama.2020.2131

72. Jeyanathan M, Afkhami S, Smaill F, Miller MS, Lichty BD. Immunological considerations for COVID-19 vaccine strategies. Nat Rev Immunol. (2020) 20:615-32. doi: 10.1038/s41577-020-00434-6

73. https://www.covid-19vaccinetracker.org/authorized-vaccines,

74. https://www.who.int/publications/m/item/draft-landscape- of-covid-19candidate-vaccines.

75. Chung YH, Beiss V, Fiering SN, Steinmetz NF. COVID-19 vaccine frontrunners and their nanotechnology design. ACS Nano. (2020) 14:1252237. doi: 10.1021/acsnano.0c07197

76. Walsh EE, Frenck RW, Jr., Falsey AR, Kitchin N, Absalon J, et al. Safety and immunogenicity of two RNA-based Covid-19 vaccine candidates. $N$ Engl J Med. (2020) 383:2439-50. doi: 10.1056/NEJMoa2027906

77. Polack FP, Thomas SJ, Kitchin N, Absalon J, Gurtman A, Lockhart S, et al. Safety and efficacy of the BNT162b2 mRNA Covid-19 vaccine. N Engl J Med. (2020) 383:2603-15. doi: 10.1056/NEJMoa2034577

78. Zhu FC, Li YH, Guan XH, Hou LH, Wang WJ, Li JX, et al. Safety, tolerability, and immunogenicity of a recombinant adenovirus type-5 vectored COVID-19 vaccine: a dose-escalation, open-label, non-randomised, first-in-human trial. Lancet. (2020) 395:1845-54. doi: 10.1016/S0140-6736(20)31208-3

79. Kamidani S, Rostad CA, Anderson EJ. COVID-19 vaccine development: a pediatric perspective. Curr Opin Pediatr. (2021) 33:144-51. doi: 10.1097/MOP.0000000000000978

80. Haynes BF, Corey L. Prospects for a safe COVID-19 vaccine. Sci Trans Med. (2020) 12:eabe0948. doi: 10.1126/scitranslmed.abe0948

81. Koirala A, Joo YJ, Khatami A, Chiu C, Britton PN. Vaccines for COVID-19: the current state of play. Paediatr Respir Rev. (2020) 35:43-9. doi: 10.1016/j.prrv.2020.06.010

82. Rauh LW, Schmidt R. Measles immunization with killed virus vaccine. serum antibody titers and experience with exposure to measles epidemic. Am J Dis Child. (1965) 109:232-7. doi: 10.1001/archpedi.1965.02090020234007

83. Singh T, Heston SM, Langel SN, Blasi M, Hurst JH, Fouda GG, et al. Lessons from COVID-19 in children: key hypotheses to guide preventative and therapeutic strategies. Clin Infect Dis. (2020) 71:2006-13. doi: $10.1093 / \mathrm{cid} / \mathrm{ciaa} 547$

Conflict of Interest: The authors declare that the research was conducted in the absence of any commercial or financial relationships that could be construed as a potential conflict of interest.

Copyright (C) 2021 Han, Li, Xiao, Yang, Wang and Wei. This is an open-access article distributed under the terms of the Creative Commons Attribution License (CC BY). The use, distribution or reproduction in other forums is permitted, provided the original author(s) and the copyright owner(s) are credited and that the original publication in this journal is cited, in accordance with accepted academic practice. No use, distribution or reproduction is permitted which does not comply with these terms. 